Sharif University of Technology
Scientia Iranica
SCIENTIA
I RAN ICA
http://scientiairanica.sharif.edu

\title{
A new method for eliminating membrane compliance in cyclic triaxial tests on gravelly soils
}

\author{
S.M. Haeri, S.A. Shahcheraghi*, and H. Sadeghi \\ Department of Civil Engineering, Sharif University of Technology, Tehran, Iran.
}

Received 27 August 2017; accepted 22 January 2018

\section{KEYWORDS}

Gravelly soil;

Cyclic triaxial test;

Membrane

compliance;

Image processing;

Liquefaction

resistance.

\begin{abstract}
A new computer-controlled flow pump is developed to continuously mitigate the adverse effects of membrane compliance in conjunction with the implementation of image processing for volume change measurement. The flow pump eliminates the membrane compliance by injecting or pumping out the required volume of water into or from the gravelly specimens to compensate for the erroneous volume change associated with the membrane compliance during undrained cyclic triaxial tests. This error is compounded in gravelly soils due to the large size of the grains and voids. In order to measure the volume of the specimen during the isotropic consolidation stage and calibrate the flow pump for cyclic loading, an image processing technique was used for measuring the volume change during the isotropic consolidation stage of loading while calculating membrane compliance associated with the amount of input water from the flow pump into the specimen. The results of image processing show that an increase in the density of the specimens leads to an increase in the ratio of volumetric skeletal strains to axial strains and a decrease in the normalized membrane penetration. The study yields promising results that minimized the errors associated with membrane compliance during undrained cyclic loading on gravels.

(C) 2019 Sharif University of Technology. All rights reserved.
\end{abstract}

\section{Introduction}

Volume changes due to membrane penetration into a cylindrical granular specimen tested in a triaxial system can lead to erroneous measurement of soil mechanical properties. This phenomenon, known as membrane compliance, significantly affects the results of undrained triaxial tests conducted on gravelly specimens [1-4]. The effect of membrane compliance becomes more pronounced as the grain size increases. As a result, ignoring such an effect in interpreting test results of granular materials, especially gravelly

\footnotetext{
*. Corresponding author.

E-mail addresses: smhaeri@sharif.edu (S.M. Haeri);

shahcheraghy@gmail.com (S.A. Shahcheraghi);

h.sadeghi@sharif.edu (H.Sadeghi)
}

doi: $10.24200 /$ sci. 2018.5076 .1082 soils, leads to erroneous results. Therefore, it is of great importance since naturally coarse-grained soils are widespread in many parts of the world. For years, it has been supposed that these materials could not liquefy. Limitations of laboratory testing techniques, such as the membrane compliance, uniformity of the specimens, and requirements for the specimen size, have contributed to the widely believed idea that gravelly soils are not liquefiable. However, there are several case histories where liquefaction of gravels and gravelly soils has been observed [5-9]. The generation of pore water pressure during undrained loading influences the membrane penetration into the specimen by membrane rebound. Membrane rebound is, in fact, the consequence of lateral outward flow of water from the central parts to the peripheral area of the specimen to compensate for membrane penetration. The compensating volume of water for membrane rebound results in a reduction in the volume of soil skeleton. Therefore, 
the assumption of constant volume during undrained loading becomes questionable under the impact of membrane compliance. In addition, changes in pore water pressure become less than they would appear under the ideal constant volume condition $[3,4,10]$. Consequently, cyclic resistance of the soil specimen will be overestimated.

Effect of membrane compliance on the results of undrained triaxial tests is a function of some factors including soil grain size and gradation, confining pressure, density, soil fabric, preparation technique, and membrane properties [2,3]. According to Evans and Seed [2] and Nicholson et al. [3], mean grain size of the soil and confining pressure have the most significant effects on the membrane compliance, and the effects of other factors appear to be marginal. In addition, a number of research studies have studied the effect of membrane compliance on monotonic shear strength (e.g., [11,12]), dynamic shear strength (e.g., [1,4,13]), and shear modulus and Poisson ratio [14].

Although some methods have been developed to account for the effect of membrane compliance on granular material in triaxial and hollow cylinder tests, there are some limitations and/or shortcomings in implementing these techniques when coarse grain soils, especially gravelly soils, are tested. As a result, the non-compliant cyclic loading resistance of gravelly soils and the behavior of such materials in natural and in-situ states cannot be easily determined. The literature review is divided into two parts; the first part summarizes previous studies on the measurement of membrane penetration, and the second part briefly reviews the research performed on mitigation of membrane compliance. This is due to the fact that some mitigation methods require measuring the amount of membrane penetration into the specimen.

\section{Previous studies on the measurement of membrane penetration}

Volume changes caused by membrane penetration into the granular soils under varying effective confining pressures were first recognized by Newland and Alley [15]. By assuming that true skeletal volume strain is equal to three times the axial strain (during hydrostatic compression or rebound of triaxial specimens), Newland and Alley [15] suggested that the volume changes caused by membrane penetration could be determined in isotropic compression tests on saturated specimens according to Eq. (1):

$$
\Delta V_{m}=\Delta V_{T}-\Delta V_{S}
$$

where $\Delta V_{m}, \Delta V_{T}$, and $\Delta V_{S}$ are volume changes caused by membrane penetration, total volume changes, and soil skeletal volume changes, respectively. $\Delta V_{T}$ can be measured by a volume change transducer during drained tests on saturated soils, and $\Delta V_{S}$ is determined by multiplying soil skeletal volumetric strain $\left(\Delta \varepsilon_{s k}=\right.$ $\left.3 \Delta \varepsilon_{a}\right)$ by the total volume of the specimen $\left(\Delta V_{T}\right)$. However, the assumption of the isotropic deformation of the specimen under isotropic loading for measuring $\Delta V_{S}$ is a challenging issue as isotropic loading of granular soils can lead to anisotropic deformation [16,17]. Therefore, a more accurate method is required to evaluate the volume changes of the specimens and volume changes caused by membrane penetration.

During the last six decades, considerable progress has been made in developing methods for measuring the amount of error arising from membrane penetration into the specimen. Roscoe et al. [18] used hydrostatic loading tests on several soil specimens where dummy brass rods of the same height and different diameters were placed coaxially inside each specimen. For different values of cell pressure, the total volume changes versus the volume of the sand specimen were plotted. As suggested by Roscoe et al. [18], the membrane penetration could be estimated by extrapolating this plot for the diameter of a rod equal to that of the specimen. The linear extrapolation for a rod diameter and the induced anisotropy in the soil specimen as a result of the inclusion of metal rod within the specimen were the main disadvantages of this method $[11,17]$. Vaid and Negussey [17] proposed another procedure to evaluate the membrane penetration based on the assumption that the specimen radial strains are equal to the axial strains (i.e., isotropic deformation) during the unloading steps of an isotropic consolidation test. Although this procedure has become the most popular one mainly because of its simplicity [3,19], the assumption of isotropic volume changes needs to be validated. For example, Seed et al. [20] showed that specimen strains were not completely isotropic during unloading; however, they tended to be more isotropic than that in loading stages. Therefore, the assumption of isotropic strains in loading and unloading stages may also lead to significant errors.

A more accurate method for determining the amount of membrane penetration is to measure the axial and radial strains directly by strain gauges and, hence, to determine the true skeletal strain. Girth belts can be used to measure the specimen radial strain accurately; however, the measurement of radial strain at only one point is not enough to stand for the average radial strain along the specimen height. At least, three belts are required to achieve this purpose. In addition to the mechanical and electrical difficulties in installing girth belt, it is almost impossible to apply this technique to smaller specimens (with the diameter equal to or smaller than $100 \mathrm{~mm}$ ). Another method that has been developed recently to measure the axial and radial strains directly is the image 
processing technique. Using high-quality images and digitizing them properly in a computer, this technique can measure the strains in triaxial tests with sufficient accuracy. Macari et al. [21] employed a method to correct the perspective and magnification effects caused by refraction of light within the triaxial cell fluid and Plexiglas. Digital image processing is, hence, used in the present study to determine the ratio between radial and axial strains during the consolidation loading stage. This ratio is used afterwards to determine the true soil skeletal volume change of the specimens and the volume changes caused by membrane penetration according to Eq. (1).

\section{Research on the mitigation of membrane compliance}

Membrane penetration is a function of the ratio of the lateral area to the volume of the specimen [1]. Therefore, a method for reducing membrane compliance effects is to increase the specimen size while keeping the height-to-diameter ratio of the specimen constant. Wong et al. [22], Martin et al. [23], and Nicholson et al. [3] used specimens with diameters of up to $300 \mathrm{~mm}$ for mitigating the effect of membrane compliance in triaxial tests on sands. However, for soils coarser than sands, even such large specimen diameters cannot effectively mitigate the effects of membrane compliance.

Other researchers, on the other hand, developed some different methods for the mitigation or elimination of the influence of membrane compliance on pore water pressure generation during various loading stages in triaxial tests, which can be classified into two major categories. The first category of eliminating the membrane compliance effects uses a post-testing correction procedure (passive methods). In these methods, results of the tests are processed after the completion of the experiment without any special modification to testing equipment and/or procedures [4,24,25]. Despite some developments, these methods may not be able to model all of the events in undrained cyclic loading, especially in the last cycles of loading of cyclic triaxial tests where the shear strains are large. In the second category, some procedures or modifications are enforced on the specimen before or during the test to eliminate the effect of membrane compliance (active methods). This category can be divided into three groups as follows.

In the methods of the first group, the lateral surface of the specimen is coated and smoothed with various materials and using a variety of procedures to prevent membrane penetration into the peripheral voids of the specimen. Chan [26] used high-density polyethylene plates to reinforce the membrane and reduce membrane penetration. Lade and Hernandez [27] placed brass plate over the specimen's surface before the second membrane was wrapped. Raju and Venkataramana [28] used greased polyethylene stripe and thin film of polyurethane to reduce membrane penetration. Although these methods reduce membrane penetration, they may not completely eliminate it. On the other hand, the stiffening effect of membrane on the axial load should be considered [2]. Kiekbusch and Schuppener [29], Lo et al. [30], and Ismail and Randolph [12] coated the specimen-membrane interfaces with a thin layer of latex rubber. This method is not applicable to gravelly soils since a thick rubber coating may be required [2] and, still, that may not completely eliminate the effect of membrane compliance.

Rashidian et al. [31] and Haeri and Shakeri [4] used fine materials (e.g. a mixture of silt, clay, and sand) to smooth the lateral surface of the specimens. According to their method, the coating material is applied to smooth the surface of the specimen after removing the mold surrounding the specimen. However, the stability of soil specimen should be assured when the mold is removed. This procedure was used by Rashidian et al. [31] for frozen gravelly specimens and by Haeri and Shakeri [4] for cemented gravelly specimens. There are, however, some limitations and/or drawbacks in these procedures. Cemented specimens can only be used for cemented soils to model the behavior of the tested material, and frozen specimens may not remain stable throughout the completion of the specimen coating and initial setup if thawing starts to happen. A double-pane mold was recently developed by Haeri et al. [32] to coat the lateral surface of soil specimens with fine-grained materials. Although membrane penetration can be significantly improved, the sidewall coating may stiffen or soften the soil specimen. However, it was experimentally shown that stiffening effects of coating on shear strength and volume changes under drained conditions in the monotonic triaxial test were negligible for strain levels below $10 \%$ in the case of gravelly soils [32].

In the methods of the second group, the slurry of water and a fine-grained material is used to sluice the coarse-grained materials [2]. The results of their study showed a significant reduction in strength of the tested sluiced material; however, there are two limitations: a) the effect of sluicing material on the strength and porewater dissipation in the specimen cannot be recognized, and b) this method can only be used for uniform coarse materials $[4,13]$.

The method in the last group in this category for the mitigation or elimination of the membrane compliance concerns injecting additional water into the specimen during the test $[1,13,28,33-35]$. The required additional water corresponds to the volume changes due to the membrane penetration in the compression stage. The error associated with membrane penetration can be correlated with the effective pressure or 
pore water pressure through a calibration isotropic pressure test program. This procedure was first manually implemented by Raju and Venkataramana [28] in monotonic tests and by Ramana and Raju [33] in cyclic tests. In each step, the volume of additional water is determined by monitoring the changes in pore water pressure during undrained loading. This is an iterative correction process that will continue until the pore water pressure is stabilized. This stepby-step procedure proved to be effective in obtaining more accurate test results by a significant reduction in membrane compliance. However, the relatively long time up to several minutes required for manual correction limited the number of iterations to two or three times in each test. Therefore, a sudden increase in pore water pressure as a result of the lack of continuity between the iterations and the obligation to performing low-frequency tests have been the major shortcomings of the manual compensation technique [13]. With the advancement of computer-controlled testing systems, the mentioned shortcomings can be overcome by using a closed-loop algorithm to allow complete and continuous mitigation of membrane compliance $[1,13]$. This methodology may apparently give satisfactory results, provided that the volume changes caused by membrane penetration are accurately measured.

In the present research, a computer-controlled flow pump is developed and utilized as an ancillary device to a cyclic triaxial apparatus to mitigate and eliminate the effect of membrane compliance during cyclic tests on gravelly soils. The image processing technique is also used to plot membrane compliance curves to provide input data to be used by the flow pump in a specific effective confining pressure.

\section{Tested material and specimen preparation}

The soil used in this study was obtained from the outskirts of the Kan River, west of Tehran. This soil mainly consists of sand and gravel and is classified as GW according to the Unified Soil Classification System (USCS) with uniformity and curvature coefficients of $C_{u}=16.7$ and $C_{c}=2.2$, respectively. Gravel content $(>4.76 \mathrm{~mm})$ is $60 \%$, and Mean grain size $\left(D_{50}\right)$ is $5.5 \mathrm{~mm}$. The maximum grain size of the tested material is limited to $12.5 \mathrm{~mm}$ to satisfy the requirement of the specimen size used. The grain size distribution of the

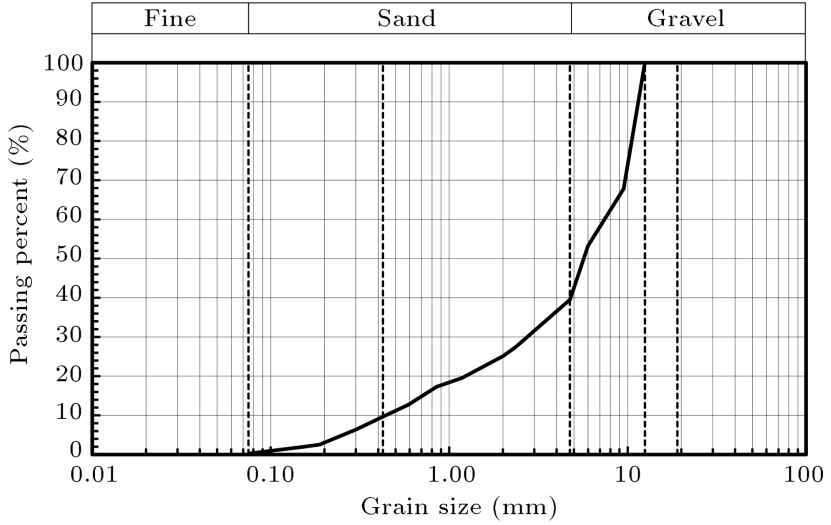

Figure 1. Grain size distribution of the tested soil.

soil is shown in Figure 1, and a summary of its physical properties is given in Table 1.

Specimens were prepared by compacting four layers of the test material with a specific density that implemented the wet tamping method in a split mold. The under-compaction procedure proposed by Ladd [36] was used to produce a uniform specimen. The water content of the compacted soil was about $5 \%$. Following the preparation of soil specimens, they were transferred inside the mold to a freezer and remained there for 18 hours. Soil specimens were then taken out from the mold. Visual observations of the specimen surface confirm that the usage of wet tamping method prevents soil segregation. The dimensions and weight of the reconstituted frozen specimens were measured. These measurements were used to determine the initial void ratio and density of each specimen. Finally, the frozen specimens were installed on the base pedestal of the triaxial apparatus for starting the main tests.

After setting up the triaxial system and applying $10 \mathrm{kPa}$ of confining pressure, the saturation of the specimen was initiated by flushing $\mathrm{CO}_{2}$ gas into the specimen for at least 20 minutes. The purpose of applying this confining pressure is to prevent the collapse of soil structure during the saturation process. The de-aired water was then flushed through the specimens gravitationally for more than four hours to melt all the frozen parts of the specimens. Saturation of the specimens was continued by applying a step-by-step back pressure scheme to obtain a B-value greater than 0.95. After the completion of saturation, the specimens were isotropically consolidated, and the volume change and the axial strain were recorded during consolidation.

Table 1. Physical properties of the tested soil.

\begin{tabular}{|c|c|c|c|c|c|c|c|c|}
\hline$D_{50}{ }^{\mathrm{i}}(\mathrm{mm})$ & $D_{10}{ }^{\mathrm{ii}}(\mathrm{mm})$ & $C_{U}{ }^{\mathrm{iii}}=D_{60} / D_{10}$ & $C_{S}{ }^{\text {iv }}$ & $\boldsymbol{G}_{s}$ & $e_{\min }$ & $e_{\max }$ & $F_{C}^{\mathrm{v}}(\%)$ & $G_{C}{ }^{\mathrm{vi}}(\%)$ \\
\hline 5.5 & 0.45 & 16.7 & 2.2 & 2.544 & 0.232 & 0.479 & 0 & 61 \\
\hline
\end{tabular}




\section{Measurement of membrane penetration}

The volume change caused by membrane penetration was evaluated by implementing both the automatic volume change device and the digital image processing technique during the isotopic consolidation tests. For this purpose, sixteen specimens with different densities were isotropically compressed up to $500 \mathrm{kPa}$ to determine the amount of membrane penetration in different pressure values. Grid lines were marked on the membranes before starting the tests to facilitate tracking the measuring points. The amount of the water seeping out of the specimens during isotropic loading was measured by the automatic volume change device, yielding the total volume change $\left(\Delta V_{T}\right)$ of the specimen. The image processing technique determines the true skeletal volume change $\left(\Delta V_{S}\right)$ of the specimen. Images of the specimen in a triaxial cell were captured every minute automatically with a precise digital camera with a resolution of 12 megapixels (2736H: $3648 \mathrm{~V})$. The results of isotropic consolidation tests are summarized in Table 2, which are described in the next paragraphs.

The multiple refraction of light rays passing through the triaxial cell fluid and the Plexiglas results in an apparent magnification of the size of the specimen. Macari et al. [21] used the two-dimensional procedure developed by Parker [37] to correct such perspective and magnification effects, a procedure which is also used in the present study. It is assumed in this procedure that a camera can be modeled as a pinhole, and the triaxial cell is perfectly cylindrical and oriented perpendicular to the axis of the pinhole camera. As the distance between the camera and the specimen increases, the perspective effect wears off, and the refraction effects over the height of the specimen are reduced [21]. In this study, the distance between the camera and the specimen was set to be about 4.0 meters. The relatively long distance between the camera and the specimen helped minimize the errors involved in the perspective and magnification effects [21]. The inner radius of the triaxial cell employed was $84.2 \mathrm{~mm}$, and its outer radius was $100.1 \mathrm{~mm}$. Figure 2 shows the variation of the true specimen radius compared with the radius calculated based on the procedure proposed by Macari et al. [21]. Details of the method of calculations can be found in Macari et al. [21]. As shown in Figure 2, the relationship between the calculated and the true radii can be assumed linear for a reasonable range of specimen radii. Therefore, the strains in the two-dimensional images taken from the specimens can be equal to the strains in the actual specimens.

Table 2. Result of isotropic consolidation test.

\begin{tabular}{|c|c|c|c|c|c|}
\hline Test no. & $D r(\%)$ & $\begin{array}{c}\text { Correction } \\
\text { ratio }\end{array}$ & $\varepsilon_{s k} / \varepsilon_{a}$ & Error (\%) & $S\left(\mathrm{~cm}^{3} / \mathrm{cm}^{2}\right)$ \\
\hline 1 & 0 & 1.000 & 2.11 & 2.76 & 0.0378 \\
\hline 2 & 0 & 0.999 & 2.18 & 3.13 & 0.0329 \\
\hline 3 & 0 & & & & 0.0315 \\
\hline 4 & 0 & 0.999 & 2.16 & 4.41 & 0.0340 \\
\hline 5 & 0 & 1.001 & 2.23 & 2.26 & 0.0300 \\
\hline Ave. & 0 & & 2.17 & & 0.0332 \\
\hline 6 & 30 & 1.000 & 2.30 & 1.38 & 0.0183 \\
\hline 7 & 30 & 1.001 & 2.49 & 1.69 & 0.0227 \\
\hline 8 & 30 & 1.001 & 2.57 & 2.35 & 0.0231 \\
\hline 9 & 30 & 1.000 & 2.31 & 1.61 & 0.0187 \\
\hline 10 & 30 & 1.000 & 2.52 & 1.82 & 0.0267 \\
\hline 11 & 30 & 1.001 & 2.35 & 4.63 & 0.0258 \\
\hline Ave. & 30 & & 2.42 & & 0.0225 \\
\hline 12 & 50 & 1.001 & 2.73 & 5.62 & 0.0154 \\
\hline 13 & 50 & 1.000 & 2.85 & 0.52 & 0.0133 \\
\hline 14 & 50 & 1.001 & 3.11 & 2.41 & 0.0190 \\
\hline 15 & 50 & 1.001 & 2.71 & 0.09 & 0.0186 \\
\hline 16 & 50 & 1.001 & 3.05 & 2.56 & 0.0203 \\
\hline Ave. & 50 & & 2.89 & 2.5 & 0.0173 \\
\hline
\end{tabular}




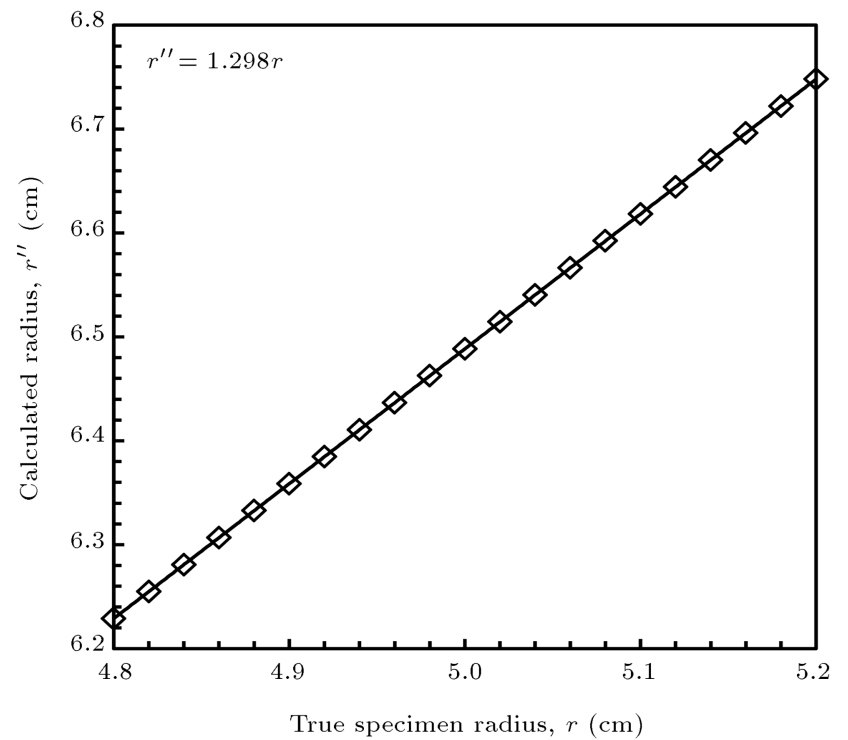

Figure 2. The variation of true specimen radius $(r)$ with calculated radius according to refraction effect of light in Plexiglas and water.

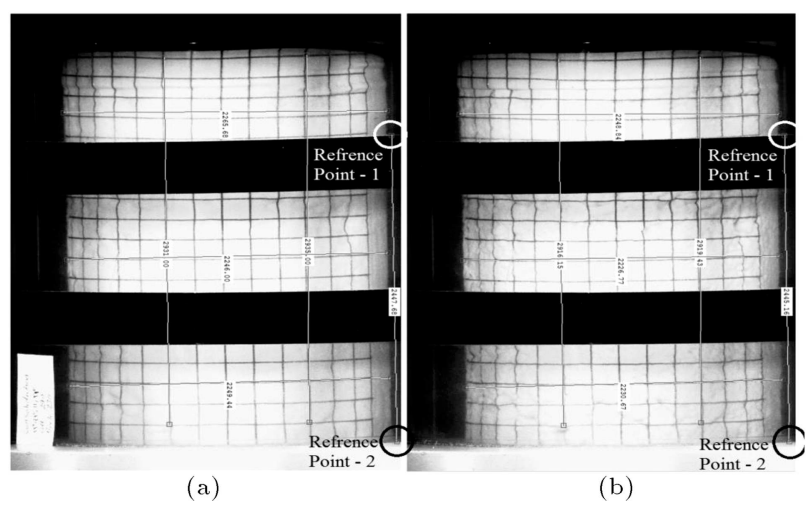

Figure 3. Using digital image processing for measuring the axial and radial strains in test no. 16. Images of specimens under confining pressure of (a) $10 \mathrm{kPa}$ and (b) $500 \mathrm{kPa}$.

For measuring the axial and radial strains, an image of a specimen with an effective confining pressure of $10 \mathrm{kPa}$ was compared with that of the specimen with that of $500 \mathrm{kPa}$ (Figure 3). More deformation or strains are induced as the pressure increases; therefore, the difference between the two images becomes more pronounced. Therefore, the high pressure difference of 10 to $500 \mathrm{kPa}$ was used to increase the accuracy of the image processing technique. In order to calibrate the image processing technique, two reference points in the longitudinal direction of the triaxial cell were selected on each image (Figure 3). The distance between the two reference points at confining pressure rates of $10 \mathrm{kPa}$ and $500 \mathrm{kPa}$ was measured as a benchmark. The ratio of these distances in the two images taken at two different cell pressures is used for calibrating the images, which is called the correction ratio. The correction ratios were revealed to be close to one, as shown in Table 2. After calibrating the images, the radial and axial strains were measured. For this purpose, three pairs of points in the radial direction and two pairs of points in the axial direction were marked on both of the images before and after consolidation (Figure 3). The three pairs of points in the radial direction were selected at the top and bottom quarter as well as the middle height of the specimen. The roughness of the specimen surface becomes highlighted as the membrane penetrates into the peripheral holes due to pressure rise. In order to omit the error induced by the roughness of the specimen in image processing, two points of three pairs were selected manually on soil grains where there was no membrane penetration and the distance between them was measured. By assuming zero strain at the top and bottom of the specimen and considering the strain measured at three levels along the specimen height, the true skeletal strain was calculated, and the ratio between the axial and the true skeletal strain was determined, as given in Table 2 .

In order to check the accuracy of this method, the axial strains measured with the image processing technique were compared with those measured with the vertical Linear Variable Differential Transformer (LVDT). The error associated with the image processing method was compared to LVDT measurement in all tests, and they are given in the last column of Table 2. The error is $2.5 \%$ on average and is limited to $6 \%$. The calculation procedure of volumetric skeletal strain using the digital image processing technique for test no. 16 is shown in Table 3 as a sample. In this study, it is assumed that the radial strains are the same in all directions. In other words, the specimens meet the axisymmetric conditions during isotropic loading. This assumption is consistent with the result of the experiments reported by Macari et al. [21]. They used two cameras in different directions to measure the radial strains during shear loading. The volume changes measured by the two cameras showed close agreement, especially in small strains.

According to the measured data shown in Table 2, the deformations of the specimens are anisotropic, and the ratio between the volumetric skeletal strains and the axial strains $\left(\varepsilon_{s k} / \varepsilon_{a}\right)$ is less than 3 . The average value of the ratio for specimens with an initial relative density of zero is 2.2 and increases by increasing the density (Figure 4). For the specimens with an initial relative density of 50 percent, $\varepsilon_{s k} / \varepsilon_{a}$ ratio is 2.9 , and the deformations in the specimens with an initial relative density of 50 percent are nearly isotropic. In other words, specimens with higher densities tend to deform more isotropically under isotropic pressure.

It can be inferred from the results of Figure 4 that the ratio between radial strain and axial strain 
Table 3. Calculation procedure of volumetric skeletal strain using digital image processing (test no. 16).

\begin{tabular}{|c|c|c|}
\hline Effective stress (kPa) & 10 & 500 \\
\hline Image no. & DSCN0005 & DSCN0154 \\
\hline Reference distance (pixel) & 2447.68 & 2445.16 \\
\hline Correction ratio & & 1.0010 \\
\hline Lateral distance - top quarter (pixel) & 2265.68 & 2248.84 \\
\hline Corrected lateral distance & 2265.68 & 2251.16 \\
\hline Lateral strain $\left(\varepsilon_{r, 1 / 4}\right)$ & & -0.6451 \\
\hline Lateral distance - middle height (pixel) & 2246.00 & 2226.77 \\
\hline Corrected lateral distance & 2246.00 & 2229.06 \\
\hline Lateral strain $\left(\varepsilon_{r, 1 / 2}\right)$ & & -0.7597 \\
\hline Lateral distance - bottom quarter (pixel) & 2249.44 & 2230.67 \\
\hline Corrected lateral distance & 2249.44 & 2232.97 \\
\hline Lateral strain $\left(\varepsilon_{r, 3 / 4}\right)$ & & -0.7376 \\
\hline Average lateral strain $\left(\varepsilon_{r}\right)$ & & -0.4285 \\
\hline Axial distance (pixel) & 2935.00 & 2919.43 \\
\hline Corrected axial distance & 2935.00 & 2922.44 \\
\hline Axial strain $\left(\varepsilon_{a}\right)$ & & -0.4298 \\
\hline Axial distance (pixel) & 2931.00 & 2916.15 \\
\hline Corrected axial distance & 2931.00 & 2919.16 \\
\hline Axial strain $\left(\varepsilon_{a}\right)$ & & -0.4058 \\
\hline Average axial strain $\left(\varepsilon_{a}\right)$ & & -0.4178 \\
\hline Skeleton volumetric strain $\left(\varepsilon_{s k}\right)$ & & -1.2748 \\
\hline$\varepsilon_{s k} / \varepsilon_{a}$ & & 3.0513 \\
\hline
\end{tabular}

increases with relative density and approaches unity for the specimens with a relative density of 50 percent. It means that dense specimens behave nearly isotropically, while the loose specimens are far from

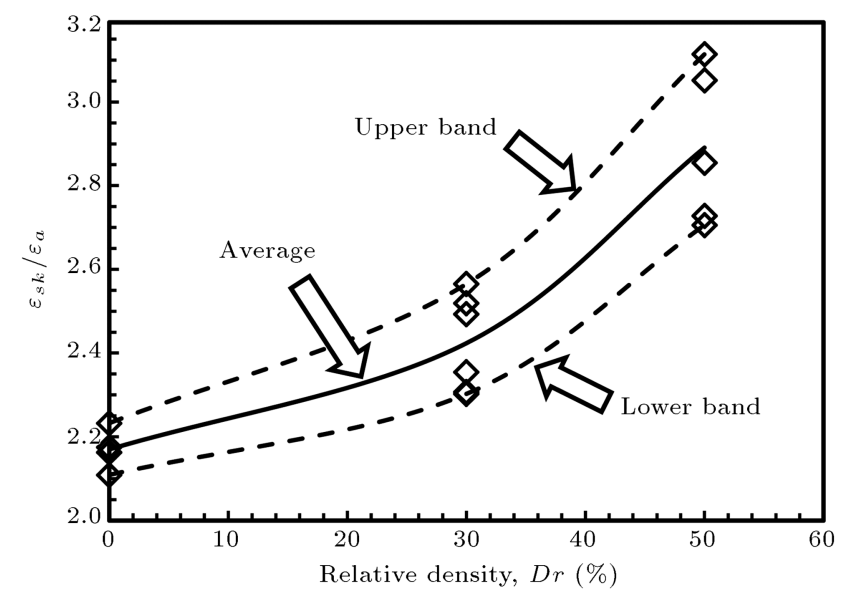

Figure 4. Variation of ratio between axial strain $\left(\varepsilon_{a}\right)$ and true skeletal strain $\left(\varepsilon_{s k}\right)$ with relative density of the specimens. behaving isotropically under isotropic pressure. In fact, deformation of a soil specimen under isotropic compression can be divided into two components: elastic deformation and plastic deformation associated with the slippage of the soil grains due to isotropic pressure. The elastic deformation, which is the main component of deformation in dense specimens, is mostly isotropic; therefore, the deformations of the dense specimens are nearly isotropic. For loose specimens, the deformation associated with slippage of soil grains is much larger than the elastic deformation. The deformation associated with slippage of soil grains is not isotropic; therefore, the deformations of loose specimens are anisotropic.

According to Eq. (1), the volume changes caused by membrane penetration can be calculated by the following equation from the results of isotropic compression tests:

$$
\Delta V_{m}=\Delta V_{T}-\Delta V_{S}=\Delta V_{T}-\frac{\varepsilon_{s k f}}{\varepsilon_{a f}} V_{T} \varepsilon_{a}
$$

where $\varepsilon_{a}$ is the axial strain, and $\varepsilon_{s k f}$ and $\varepsilon_{a f}$ are 
true skeletal and axial strains, respectively, in the final step of the isotropic compression stage. Digital image processing was implemented to measure the skeletal strains at the end of the compression process, and the specimen axial strain was measured continuously by the LVDT during the test. Since the cyclic axial loadings were applied on the specimens that were compressed under $100 \mathrm{kPa}$ (details of cyclic tests are reported in the next section), the membrane penetration curves obtained for confining pressures of up to $100 \mathrm{kPa}$, as shown in Figure 5, have been used. There is a linear correlation between the unit membrane compliance $\left(\Delta B_{m}=\Delta \varepsilon_{m} \cdot V_{T} / A_{m}\right)$ and the effective confining pressure $\left(\sigma_{3}^{\prime}\right)$ on a logarithmic scale [4,13,25,38-41], where, $\Delta B_{m}$ is the unit membrane compliance, $A_{m}$ is the total lateral surface area of the specimen. The slope of the graph of unit membrane compliance versus $\log \sigma_{3}^{\prime}$ is called normalized membrane penetrations $(\mathrm{S})$ :

$$
S=\frac{\Delta B_{m}}{\Delta \log \sigma_{3}^{\prime}} \text {. }
$$

The results of isotropic compression tests on the specimens with different initial relative densities are shown in Figure 5. For each test, the normalized membrane penetration $(S)$ was determined by curve fitting and calculated according to Eq. (3). The normalized membrane penetrations $(S)$ are collected in Table 2 for the tested material. In this table, the average values of the normalized membrane penetrations are shown for different initial densities.

Seed et al. [20] suggested that changes in the density of sand specimens for cases with extremely high to extremely low densities should not change the value of $S$ more than 10 percent. Tokimatsu and Nakamura [24] and Nicholson et al. [3] reported similar results for sand. Although most of the previous studies on sands suggest that the influence of the density of specimens on membrane penetration and $S$ value is small with relatively minor significance, results of this study indicate that the effect of the density of the specimens on the membrane penetration is significant in the case of gravels. As shown in Figure 6, the normalized membrane penetration or $S$ values decrease with increasing density. According to the results, the average value of the normalized membrane penetration for the specimens with the initial relative density of zero is $0.0332 \mathrm{~cm}^{3} / \mathrm{cm}^{2}$, while this value decreases to $0.0225 \mathrm{~cm}^{3} / \mathrm{cm}^{2}$ for the specimens with an initial relative density of $30 \%$ and reaches $0.0173 \mathrm{~cm}^{3} / \mathrm{cm}^{2}$ for the specimens with an initial relative density of $50 \%$. This is in agreement with the results of Raju and Venkataramana [28] and Ramana and Raju [38], indicating that there is a significant difference in the volume changes due to the membrane penetration measured for the specimens of uniform sand with different densities. The result of their study shows that the volume changes

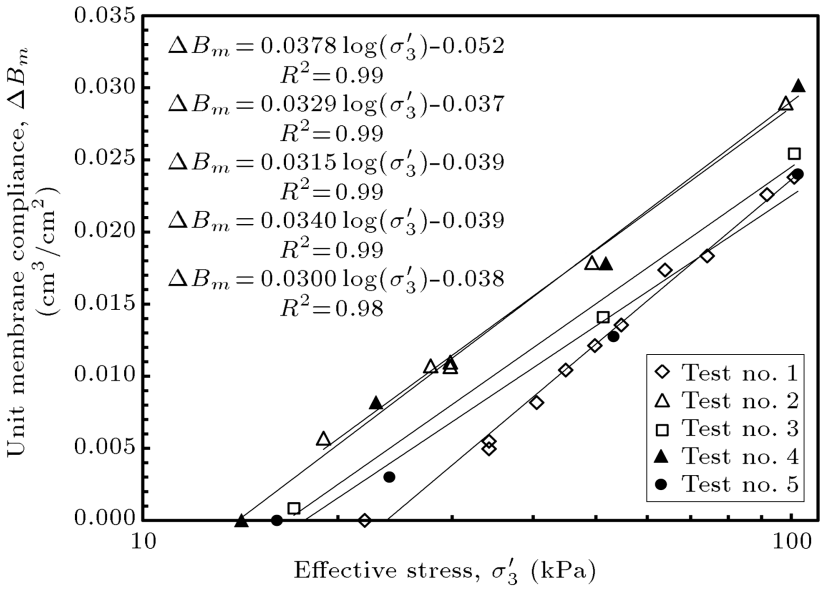

(a) $D r=0$

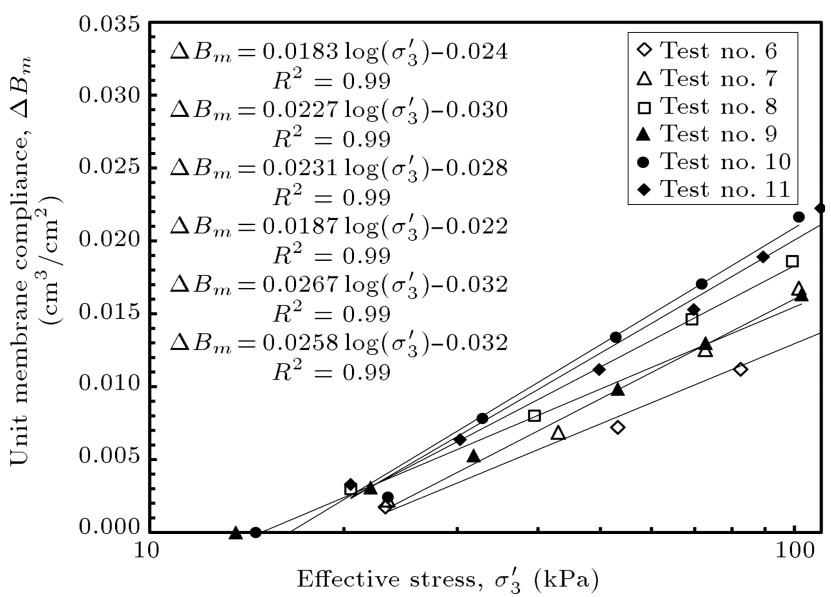

(b) $\mathrm{Dr}=30 \%$

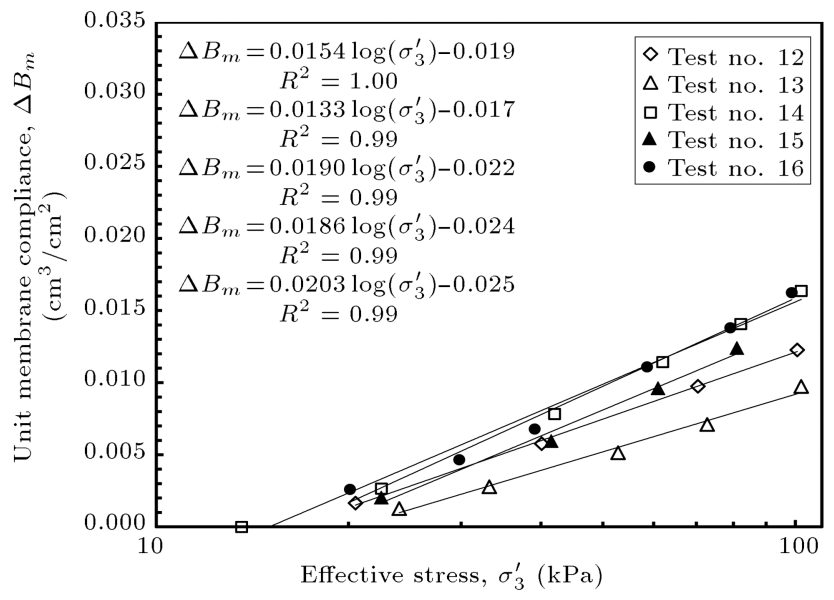

(c) $D r=50 \%$

Figure 5. Membrane penetration curve obtained from isotropic consolidation test for specimens with different initial relative densities: (a) $D r=0$, (b) $D r=30 \%$, and (c) $\mathrm{Dr}=50 \%$.

due to the membrane penetration of loose specimens are more than those of dense specimens.

In Figure 7, the values of the normalized membrane penetration of this study are compared with those of the previous studies $[2,4,13,17,22-24,27$, 


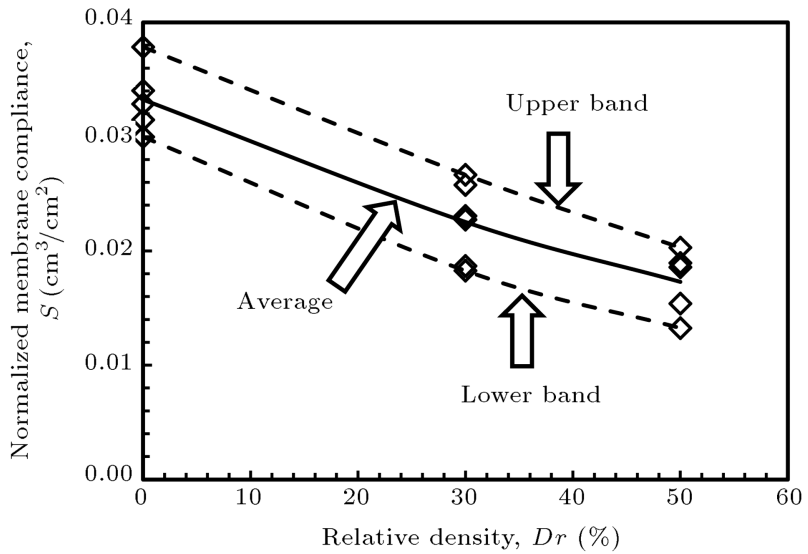

Figure 6. Variation of normalized membrane compliance $(S)$ with relative density of the specimens.

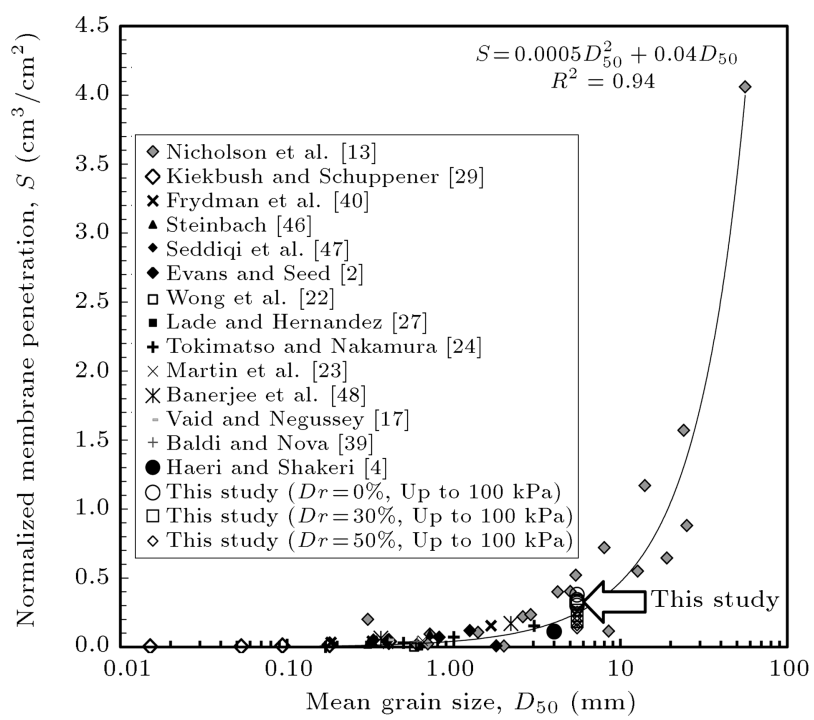

(a)

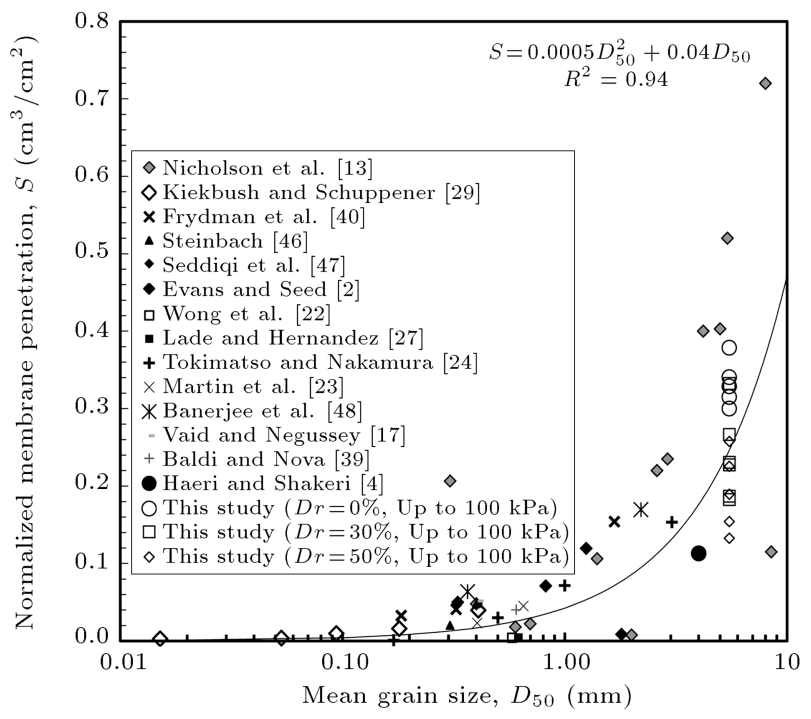

(b)

Figure 7. Comparison of measured normalized membrane penetration with that of previous studies: (a) All data and (b) data with mean grain size less than $10 \mathrm{~mm}$.
29,39,40,46-48]. The present test results appear to fall into the range of data reported in the literature. Data follow the second-order polynomial function with some scattering. The scattering of the normalized membrane penetration data reported by other researchers (Figure 7) may result from the differences in density of the tested materials. However, more experimental tests are required on different soil specimens to quantify the effect of the density of soil on normalized membrane penetration.

\section{Development of a computer-controlled flow pump for eliminating the effect of membrane compliance}

In this study, a computer-controlled flow pump was developed to compensate for the erroneous volume change associated with the membrane compliance during undrained cyclic triaxial tests on gravelly soils by injecting or pumping the required volume of water into or from the specimens (Figure 8). The flow pump was connected to a standard cyclic triaxial apparatus, as shown in Figure 9. This technique is based on the fact that the volumetric error resulting from membrane penetration is a function of the effective confining pressure. The volume change due to the membrane penetration at each confining pressure is determined by the normalized membrane penetration or $S$ value. As described in the previous section, the normalized membrane penetration is measured by isotropic compression tests and the image processing technique for specimens with different initial relative densities. The normalized membrane penetration or $S$ value obtained through Eq. (3) is used as an input for the flow pump. To assure the constant-volume conditions during the undrained tests on saturated specimens, the volume change caused by membrane penetration is compensated by flow pump operation during the test continuously. This volume change at the current effective confining pressure is calculated from the membrane compliance curves obtained from isotropic tests (Table 2 and Figure 6). The corresponding effective confining pressure is calculated from continuous measurements of the pore water pressure. These procedures are run in a computer program that was designed to control the flow pump through a feedback system for compensation of volume changes due to membrane penetration.

The specimens used for cyclic triaxial test were prepared in the same way as those used for isotropic compression tests. These specimens were consolidated to $100 \mathrm{kPa}$ confining pressure after saturation. Cyclic loading was applied to all of the specimens under the undrained condition in a stress-controlled mode with a frequency of $0.04 \mathrm{~Hz}$ and a sinusoidal form. To determine the effect of membrane compliance, the 


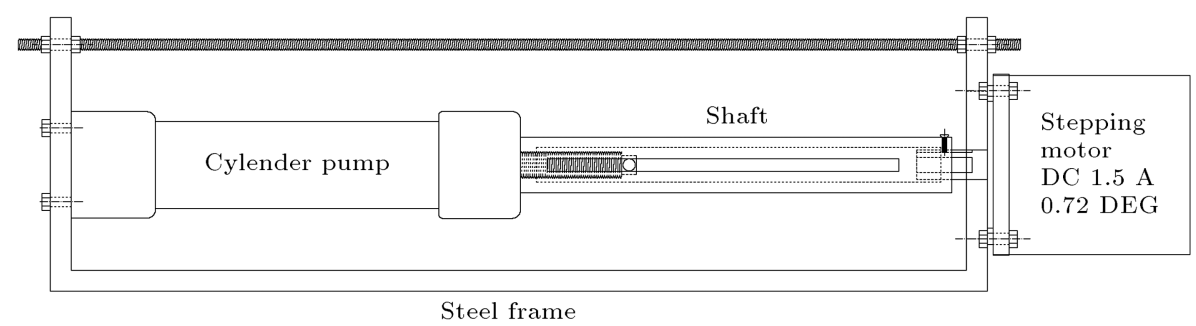

Figure 8. The newly developed flow pump composed of a cylindrical pump and a stepping electric motor.

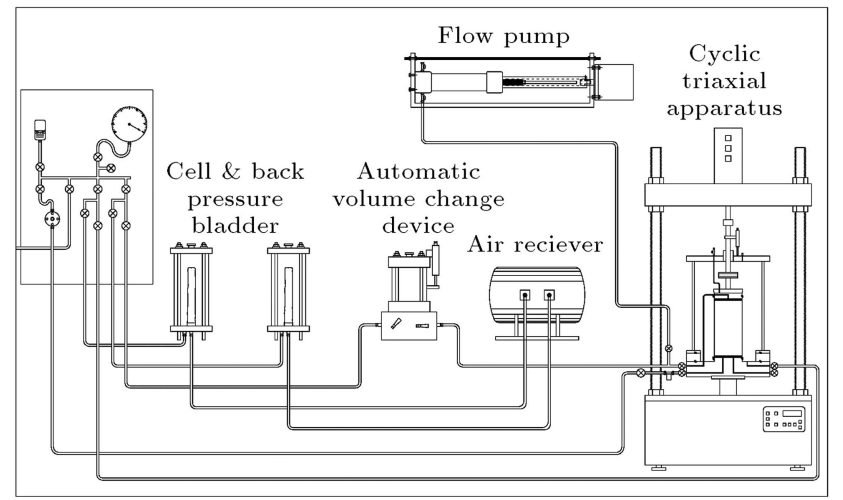

Figure 9. Schematic diagram of the cyclic triaxial apparatus equipped with the flow pump.

computer-controlled flow pump was used in a series of tests to eliminate the effect of membrane compliance. The results of these tests are compared with those of the second series of tests carried out with standard cyclic triaxial tests in which membrane compliance was not considered.

The variations of pore water pressure generation and axial strain with the number of cycles during cyclic loading for specimens with and without elimination of membrane compliance are depicted in Figure 10. In this figure, a curve is for a specimen with elimination of membrane compliance using the flow pump and the membrane penetration curves resulting from the image processing technique (as shown in Figure 5). Another curve is also for a specimen with elimination of membrane compliance using the flow pump while assuming that the deformation of the specimen is isotropic during isotropic compression. The results of these tests are compared with those of the standard cyclic triaxial test without any membrane compliance measure. According to the results shown in Figure 10, the rate of pore pressure generation of the specimen in the standard cyclic triaxial test (without membrane compliance elimination) is significantly reduced due to elimination of the effect of membrane compliance. Therefore, the number of cycles required to trigger the threshold liquefaction in the specimen without elimination of the effect of membrane compliance in the reported tests is eight times that of the specimen for which the flow pump and image processing technique

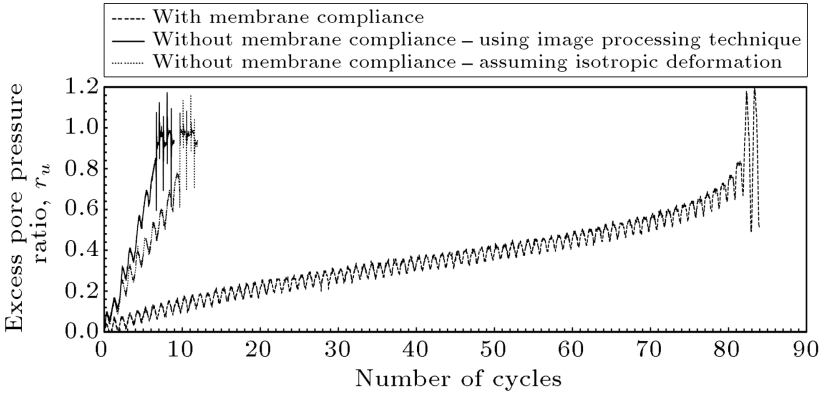

(a)

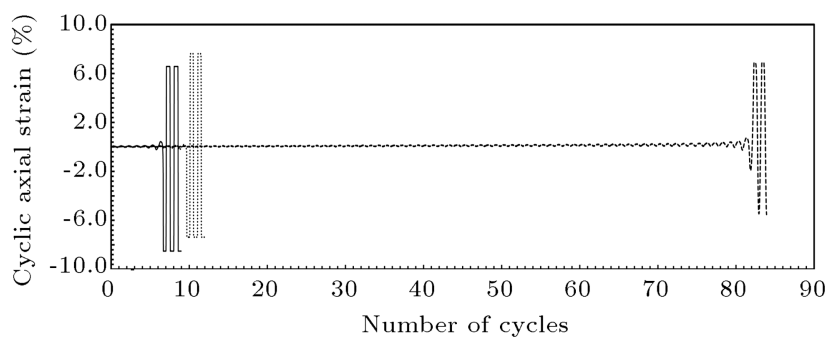

(b)

Figure 10. The variation of (a) pore water pressure generation and (b) axial strain with the number of cycles during cyclic loading for specimens with and without elimination of membrane compliance (confining pressure $=$ $100 \mathrm{kPa}$ and double amplitude stress $=50 \mathrm{kPa})$.

are used to compensate the effect of membrane compliance. It can be concluded that the cyclic resistance of gravelly soils may be overestimated if the error caused by membrane compliance is not eliminated.

The assumption of isotropic strains in gravelly soils leads to the overestimation of the skeletal volume change of the specimen and underestimation of the volume changes due to membrane penetration. Accordingly, measurements reveal that the ratio of skeletal strain to axial strain is less than three for the loose material tested in this study. This assumption, also, leads to the overestimation of cyclic resistance of the specimens, compared to the specimen tested by implementing membrane penetration curve, which is obtained with the digital image processing technique. For example, the specimen with a particular membrane compliance curve obtained with the digital image processing technique was liquefied in seven cycles; however, the specimen with the membrane compliance 
curve obtained by assuming isotropic deformations was liquefied in ten cycles.

\section{Effect of membrane compliance on cyclic resistance and pore water pressure generation}

In order to evaluate the effectiveness of the newly developed flow pump, two sets of undrained cyclic triaxial tests have been performed on reconstituted specimens of gravelly soils without and with elimination of membrane compliance by utilizing the flow pump. The membrane penetration curve used to control the flow pump to eliminate the membrane compliance is obtained from the results of the image processing technique. The tests were conducted on specimens with $100 \mathrm{~mm}$ diameter and $200 \mathrm{~mm}$ height, and various sinusoidal cyclic deviatoric stresses were applied under a confining pressure rate of $100 \mathrm{kPa}$. In Figure 11, variations in the number of cycles required for failure are shown against Cyclic Stress Ratio (CSR) for specimens with and without the elimination of membrane penetration. Initial liquefaction has been observed during the tests with or without elimination of membrane compliance; however, the number of cycles for triggering the initial liquefaction is higher for the specimens without elimination of the effect of membrane compliance. The liquefaction curve of specimens with elimination of membrane compliance shifts downward in Figure 11 as a result of membrane compliance elimination without any changes in the shape of the curves, and the slopes of the two curves are almost the same. Similar results were reported by Tokimatsu and Nakamura [24].

Pore pressure generation in the specimens without elimination of the effect of membrane compliance is shown in Figure 12(a). Similar results for the specimens with elimination of membrane compliance are shown in Figure 12(b). As shown in Figure 12, the trends of pore pressure generation are different for the specimens with and without elimination of membrane compliance. In the specimens without elimination of membrane compliance, the development of pore water pressure with the normalized number of stress cycles is highly non-uniform following an inverse buildup trend. There is a sharp rise in pore water pressure at the beginning of cyclic loading followed by a gentler slope and again an increase towards the failure (Figure 12(a)). However, in the specimens with elimination of membrane compliance, the pore water pressure increases more uniformly with the normalized stress cycles following a more linear trend (Figure 12(b)). The shape of the pore water pressure generation curve in the specimens with elimination of membrane compliance is similar to the results of tests on sand with more than $30 \%$ non-plastic silt reported

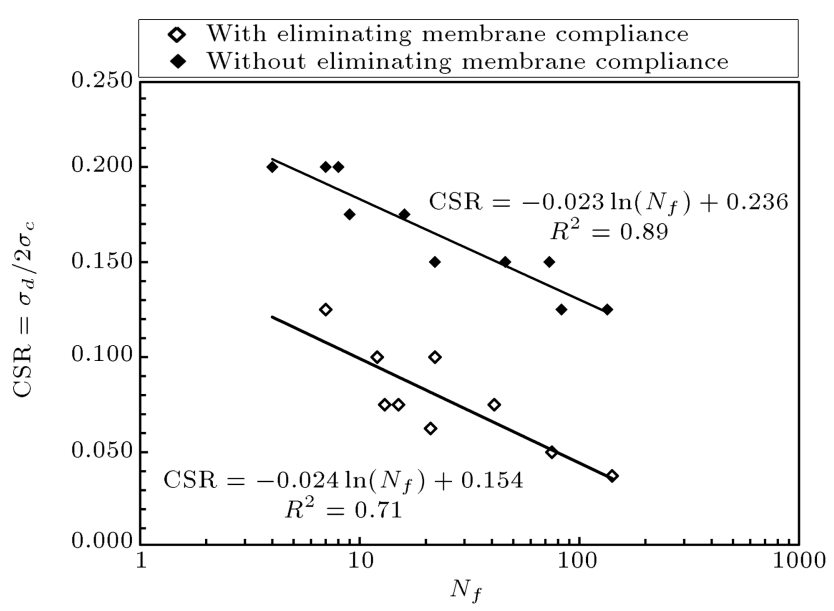

Figure 11. Comparison of cyclic stress resistance of specimens with and without elimination of membrane compliance.

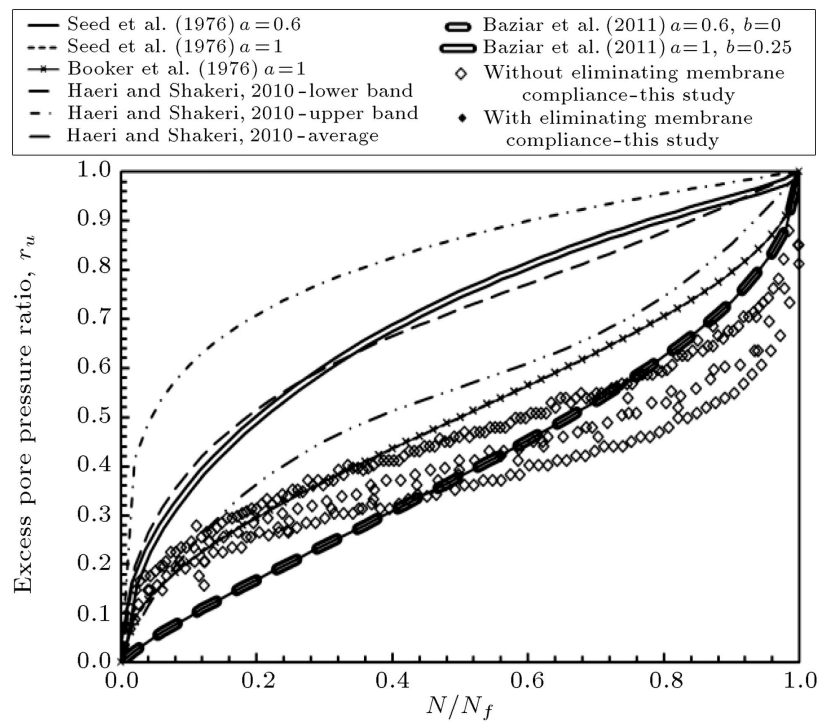

(a)

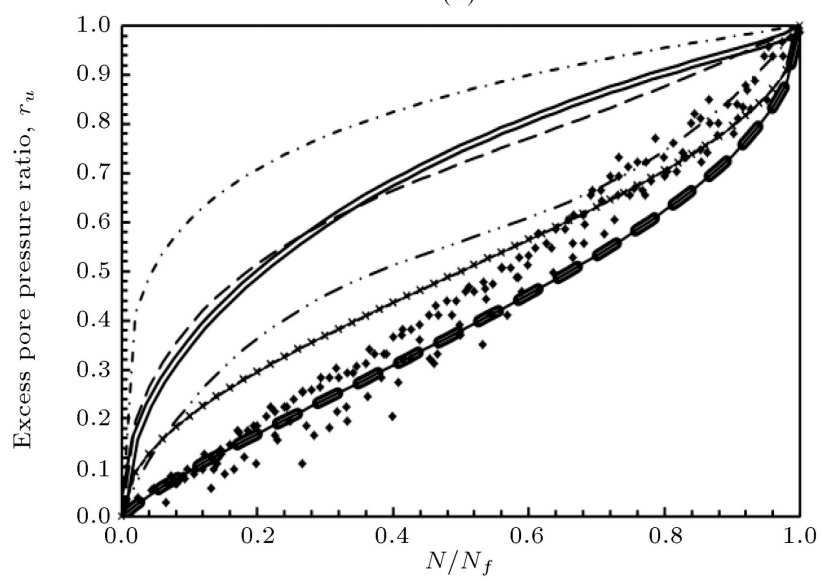

(b)

Figure 12. Comparison of the variation of excess pore water pressure ratio versus the normalized number of stress cycles in test results of current study with the models developed by other researchers: (a) Without and (b) with elimination of membrane compliance. 
by Baziar et al. [42]. It might be concluded that the shape of the pore pressure generation curve in mixed non-plastic granular soils (mixture of sand and nonplastic silt and mixture of gravel and sand) is more uniform than that for uniformly graded soils like clean sand or gravel.

A number of models for predicting the generation of pore water pressure during cyclic loading have been presented by various researchers such as Seed et al. [43] (Eq. (4)), Booker et al. [44] (Eq. (5)), and Haeri and Shakeri [4] (Eqs. (6)-(8)).

$$
\begin{aligned}
& r_{u}=\frac{1}{2}+\frac{1}{\pi} \arcsin \left(2\left(\frac{N}{N_{f}}\right)^{\frac{1}{a}}-1\right), \\
& r_{u}=\frac{2}{\pi} \arcsin \left(\left(\frac{N}{N_{f}}\right)^{\frac{1}{2 a}}\right), \\
& r_{u}=\left[2\left(\frac{N}{N_{f}}\right)^{3}-3\left(\frac{N}{N_{f}}\right)^{2}+2\left(\frac{N}{N_{f}}\right)\right]^{\frac{1}{a}}
\end{aligned}
$$

$a=1.2$ for lower bound,

$r_{u}=1-\cos \left(\frac{\pi}{2}\left(\frac{N}{N_{f}}\right)^{\frac{1}{a}}\right)$

$a=7.7$ for upper bound,

$r_{u}=\left[1.65\left(\frac{N}{N_{f}}\right)^{4}-2.3\left(\frac{N}{N_{f}}\right)^{3}+1.65\left(\frac{N}{N_{f}}\right)^{2}\right]^{\frac{1}{a}}$,

$a=4.5$ for average value.

These models predict the pore pressure ratio $\left(r_{u}\right)$ as a function of the ratio of the number of the applied uniform cycles of loading $(N)$ to the number of cycles causing liquefaction $\left(N_{f}\right)$. In addition, an empirical parameter, $a$, has been used in these models, which is a function of the soil properties and the test conditions, and can be obtained by curve fitting.

In all of these models, the pore water pressure is building up much faster at the beginning of cyclic loading, and the rate of pore water pressure generation decreases by increasing cyclic loading. Therefore, it cannot fit experimental results, especially for the specimens with elimination of membrane compliance. A comparison of test results of the current research on the specimens without and with the elimination of membrane compliance with those of the other researchers is presented in Figure 12(a) and (b), respectively. As shown in Figure 12, the prediction results of pore water pressure generation associated with these models are different from the results of the tests obtained from this study. In particular, the pore water pressure generations in the specimens with elimination of the effect of membrane compliance in this study do not completely match the predictions from models proposed by others.

The models presented by most researchers are based on test results on clean sand (e.g., [43]), sandy soils (e.g., [45]), or a mixture of sand and silt [42]. The model developed by Haeri and Shakeri [4] is based on test results of gravelly soil. Note that a post-testing correction procedure was used in their research to eliminate the effect of membrane compliance. As previously shown, this model can generally predict the cyclic resistance of gravelly soils; however, it may not be able to capture all of the detailed events in undrained cyclic loading. For example, the real soil behavior during the last cycles of loading cannot be described by this model because of the special methodology used for post-test correction of cyclic resistance. In other words, there are some shortcomings and limitations on previous models to predict the pore water pressure generation during cyclic loading on the tested material, especially for the specimens with elimination of the effect of membrane compliance. Therefore, a new model is encouraged for a more precise prediction of pore water pressure generation in gravelly soils during cyclic loading.

The pore water pressure generation graphs for specimens with elimination of membrane compliance can be modeled by the following simple equation:

$$
r_{u}=\left(\frac{N}{N_{f}}\right)^{\frac{1}{a}} .
$$

As shown in Figure 13(b), Eq. (9) is suitable with $a=0.55$ for the lower bound and $a=1.1$ for the upper bound for the specimens with elimination of membrane compliance. Note that this simplified model is just a

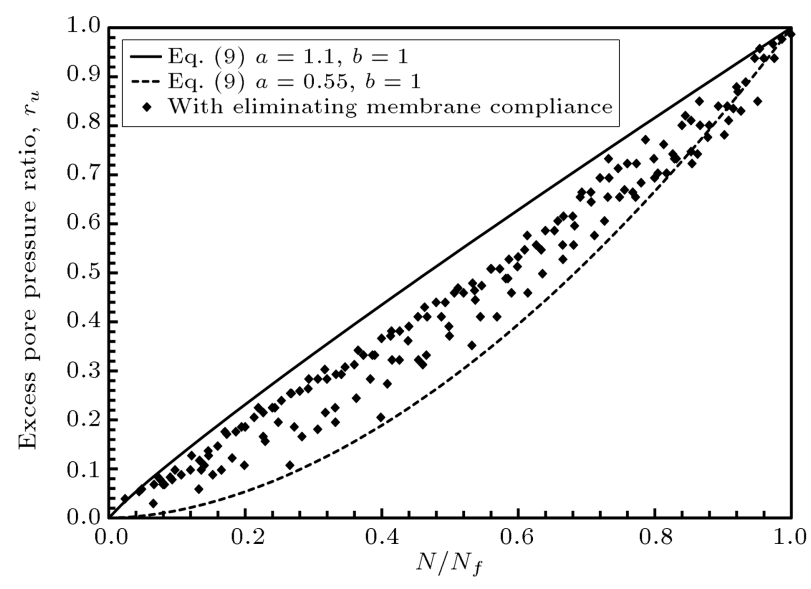

Figure 13. Modeling the variation of excess pore water pressure ratio versus the normalized number of stress cycles for specimens: (a) Without and (b) with elimination of membrane compliance. 
proposal to simulate the observed trend of pore pressure generation for the test conditions in this study. In other words, further experimental results are required to validate the proposed model for more comprehensive testing conditions. Since modeling is not one of the main goals of this research, further studies are required to reveal differences in the mechanism of pore water pressure generation in gravelly soils and clean sand. A comprehensive test program is going to achieve this purpose in the future.

\section{Conclusions}

The volume change in isotropic consolidation tests was measured by a digital image processing technique, and the membrane penetration curve of the specimens with different relative densities was determined. A new computer-controlled flow pump was developed to eliminate membrane compliance in cyclic triaxial tests during cyclic loading in conjunction with the implementation of image processing for volume change measurement. Based on the results, the following conclusions can be drawn:

1. It was shown that image processing could be effectively used to evaluate the volume change due to membrane penetration;

2. Deformation of the gravelly specimens under hydrostatic loading was not isotropic, and the ratio of volumetric skeletal strain and axial strain $\left(\varepsilon_{s k} / \varepsilon_{a}\right)$ was lower than 3 . This ratio for specimens with a density as low as zero was 2.2 and increased with increasing density. In the specimens with an initial density of 50 percent, for example, the ratio of $\varepsilon_{s k} / \varepsilon_{a}$ was 2.9 , and the behavior of the specimens was nearly isotropic;

3. The normalized membrane penetration or $\mathrm{S}$ value decreased with increasing density;

4. Membrane compliance had a significant effect on the cyclic resistance of the specimens. This phenomenon caused an increase in cyclic resistance of the specimens;

5. The assumption of the isotropic deformation during the isotropic compression led to the underestimation of the effect of membrane compliance, and this assumption caused an increase in the resistance of the specimens as compared to the specimen tested with the calibrated membrane penetration curve obtained with the digital image processing technique.

\section{Acknowledgments}

All of the tests were conducted in the Advanced Geotechnical Engineering Laboratory of Civil Engineering Department at Sharif University of Technology.
In addition, the financial support of Vice Presidencies in Research and Graduate Studies of the Sharif University of Technology is acknowledged. The last author is grateful to Sharif University of Technology and Iran's National Elites Foundation for providing financial support to him as a post-doctoral research fellow.

\section{References}

1. Tokimatsu, K. and Nakamura, K. "A liquefaction test without membrane penetration effects", Soils Found., 26(4), pp. 127-138 (1986).

2. Evans, M.D. and Seed, H.B. "Undrained cyclic triaxial testing of gravels-the effect of membrane compliance", Report No. UCB/EERC-87/08, University of California, Berkeley, Earthq. Eng. Res. Cent. (1987).

3. Nicholson, P.G., Seed, R.B., and Anwar, H.A. "Elimination of membrane compliance in undrained triaxial testing I: measurement and evaluation", Can. Geotech. J., 30, pp. 727-738 (1993).

4. Haeri, S.M. and Shakeri, M.R. "Effect of membrane compliance on cyclic resistance of gravelly sand", Geotech. Test. J., 33(5), pp. 1-10 (2010).

5. Harder, L.F. and Seed H.B. "Determination of penetration resistance for coarse-grained soils using the Becker hammer drill", Report No. UCB/EERC-86/06, University of California, Berkeley, Earthq. Eng. Res. Cent. (1986).

6. Yegian, M.K., Ghahraman, V.G., and Harutiunyan, R.N. "Liquefaction and embankment failure case histories, 1988 Armenia Earthquake", J. Geotech. Eng., ASCE, 120(3), pp. 581-596 (1994).

7. Sirovich, L. "Repetitive liquefaction at a gravelly site and liquefaction in overconsolidated sands", Soils Found., 36(4), pp. 23-34 (1996).

8. Hatanaka, M., Uchida, A., and Ohara, J. "Liquefaction characteristics of a gravelly fill liquefied during the 1995 Hyogo-Ken Nanbu earthquake", Soils Found., 37(4), pp. 107-115 (1997).

9. Cao, Z., Youd, T.L., and Yuan X. "Gravelly soils that liquefied during 2008 Wenchuan, China earthquake, Ms=8.0", Soil Dyn. Earthq. Eng., 31, pp. 1132-1143 (2011).

10. Evans, M.D. "Density changes during undrained loading-membrane compliance", J. Geotech. Eng., ASCE, 118(12), pp. 1924-1936 (1992).

11. Raju, V.S. and Sadasivan, S.K. "Membrane penetration in triaxial tests on sands", J. Soil Mech. Found. Div., 100, pp. 482-489 (1974).

12. Ismail, M.A. and Randolph, M.F. "Pseudo anisotropy induced by membrane compliance in cemented granular soils", Soils Found., 45(3), pp. 39-49 (2005).

13. Nicholson, P.G., Seed, R.B., and Anwar, H.A. "Elimination of membrane compliance in undrained triaxial testing II: mitigation by injection compensation", Can. Geotech. J., 30, pp. 739-746 (1993). 
14. Yamashita, S., Toki, S., and Suzuke, T. "Effects of membrane penetration on modulus and Poisson[s ratio for undrained cyclic triaxial condition", Soils Found., 36(4), pp. 127-133 (1996).

15. Newland, P.L. and Alley, B.H. "Volume change during drained triaxial testes on granular materials", Geotechnique, 7(1), pp. 17-34 (1957).

16. El-shoby, M.A. and Andrawes, K.Z. "Deformation characteristics of granular materials under hydrostatic compression", Can. Geotech. J., 9, pp. 338-350 (1972).

17. Vaid, Y.P. and Negussey, D. "A critical assessment of membrane penetration in the triaxial test", Geotech. Test. J., 7, pp. 70-76 (1984).

18. Roscoe, K.H., Schofield, A.N., and Thurairajah, A. "An evaluation of test data for selecting a yield criterion for soils", Lab. Shear Test. Soils, Spec. Tech. Pub., 361, Philadelphia, pp. 111-128 (1963).

19. Verdugo, R. "Characterization of sandy soil behavior under large deformation", $\mathrm{PhD}$ Thesis, University of Tokyo (1992).

20. Seed, R.B., Anwar, H.A., and Nicholson, P.G. "Evaluation and mitigation of membrane compliance effects in undrained testing of saturated soils", Report No. SU/GT/89-01 Stanford University, Geotech. Research (1989).

21. Macari, E.J., Parker, J.K., and Costes, N.C. "Measurement of volume changes in triaxial tests using digital imaging techniques", Geotech. Test. J., 2(1), pp. 103109 (1997).

22. Wong, R.T., Seed, H.B., and Chan, C.K. "Cyclic loading liquefaction of gravelly soils", J. Geotech. Eng., ASCE, 101(6), pp. 571-583 (1975).

23. Martin, G.R., Finn, W.D.L., and Seed, H.B. "Effects of system compliance on liquefaction tests", J. Geotech. Eng. Div., ASCE, 104(GT 4), pp. 463-479 (1978).

24. Tokimatsu, K. and Nakamura, K. "A simplified correction for membrane compliance in liquefaction tests", Soils Found., 27(4), pp. 111-122 (1987).

25. Ansal, A.M. and Erken, A. "Posttesting correction procedure for membrane compliance effects on pore pressure", J. Geotech. Eng., 122(1), pp. 27-38 (1996).

26. Chan, C.K. "Membrane for rockfill triaxial testing", Technical Note, J. Soil Mech. Found. Div., ASCE, 98(SM8), pp. 849-854 (1972).

27. Lade, P.V. and Hernandez, S.B. "Membrane penetration effects in undrained tests", J. Geotech. Eng., ASCE, 103(2), pp. 109-125 (1977).

28. Raju, V.S. and Venkataramana, K. "Undrained triaxial tests to assess liquefaction potential of sands: effect of membrane penetration", Proc. Int. Symp. Soils Under Cyclic and Transient Load., 2 (1980).

29. Kiekbusch, M. and Schuppener, B. "Membrane penetration and its effect on pore water pressures," $J$. Geotech. Geoenviron. Eng., 103(11), pp. 1267-1279 (1977).
30. Lo, S.C.R., Chu, J., and Lee, I.K. "A technique for reducing membrane penetration and bedding errors", Geotech. Test. J., 12(4), pp. 311-316 (1989).

31. Rashidian, M., Ishihara, K., Kokusho, T., Kanatani, M., and Okamoto, T. "Undrained shearing behavior of very loose gravelly soils", Geotech. Spec. Pub., 56, pp. 77-91 (1995).

32. Haeri, S.M., Raeesi, R., and Shahcheraghi, S.A. "Elimination of membrane compliance using fine sandy coating on gravelly soil specimens", 5th Int. Conf. Geotech. Eng. Soil Mech., Tehran, Iran (2016).

33. Ramana, K.V. and Raju, V.S. "Constant-volume triaxial tests to study the effects of membrane penetration", Geotech. Test. J., 4(3), pp. 117-122 (1981).

34. Evans, M.D. and Zhou S. "Liquefaction behavior of sand-gravel composites", J. Geotech. Eng., ASCE, 121(3), pp. 287-298 (1995).

35. Sivathayalan, S. and Vaid, Y.P. "Truly undrained response of granular soils with no membrane-penetration effects", Can. Geotech. J., 35(5), pp. 730-739 (1998).

36. Ladd, R.S. "Preparing of test specimens using undercompaction", Geotech. Test. J., GTJODJ, 1(1), pp. 16-23 (1978).

37. Parker, J.K. "Image processing and analysis for the mechanics of granular materials experiment", ASME Proc. 19th SE Symp. Syst. Theory, Nashville, TN, March 2, ASME, Ney York (1987).

38. Ramana, K.V. and Raju, V.S. "Membrane penetration in triaxial tests", J. Geotech. Eng., ASCE, 108, pp. 305-310 (1982).

39. Baldi, G. and Nova, R. "Membrane penetration effects in triaxial testing", J. Geotech. Eng., ASCE, 110(3), pp. 403-420 (1984).

40. Frydman, S., Zeitlen, J.G., and Alpan, I. "The membrane effect in triaxial testing of granular soils", $J$. Test. Eval., 1(1), pp. 37-41 (1973).

41. Kramer, S.L., Sivaneswaran, N., and Davis, R.O. "Analysis of membrane penetration in triaxial test", J. Eng. Mech., 116(4), pp. 773-789 (1990).

42. Baziar, M.H., Shahnazari, H., and Sharafi, H. "A laboratory study on the pore pressure generation model for Firouzkooh silty sands using hollow torsional test", Int. J. Civ. Eng., 9(2), pp. 126-134 (2011).

43. Seed, H.B., Martin, P.P., and Lysmer, J. "The generation and dissipation of pore water pressures during soil liquefaction", Report No. EERC 75-26, Univ. of California, Berkeley, Calif (1975).

44. Booker, J.R., Rahman, M.S., and Seed, H.B. "GADFLEAA computer program for the analysis of pore pressure generation and dissipation during cyclic or earthquake loading", Report No. EERC76-24, University of California, Berkeley, Earthq. Eng. Res. Cent. (1976).

45. Lee, K.L. and Albaisa, A. "Earthquake induced settlements in saturated sands", J. Geotech. Eng. Div Division, ASCE, 100(GT 4), pp. 387-406 (1974). 
46. Steinbach, J. "Volume changes due to membrane penetration in triaxial tests on granular materials", M.Sc. Thesis, Cornell University, Ithaca, N.Y. (1967).

47. Siddiqi, F.H., Seed, R.B., Chan, K.C., Seed, H.B., and Pyke, R.M. "Strength evaluation of coarsegrained soils", Earthquake Engineering Research Center, Berkeley, California, Report No. UCBIEERC$87 / 22$ (1987).

48. Banerjee, N.G., Seed, H.B., and Chan, C.K. "Cyclic behavior of dense coarse-grained materials in relation to the seismic stability of dams", University of California, Berkeley, Earthquake Engineering Research Center, Report UBCJEERC-79/13 (1979).

\section{Biographies}

Seyed Mohsen Haeri, born in 1954 in Tehran, has been a Professor of Civil Engineering, Geotechnical Division, at Civil Engineering Department of Sharif University of Technology, Tehran since 1992. In addition, he has been the Director of Geotechnical Engineering Studies and Research Center (GESRC) of Sharif University of Technology since 2004. He has also served as the Past Chairman of the Civil Engineering Department (2011-2013) and Ex-Director of the Earthquake Engineering Research Center at Sharif University of Technology (1997-2003) who completed and established the Earthquake Simulator Laboratory with a large scale $4 \mathrm{~m} \times 4 \mathrm{~m} 3 \mathrm{DOF}$ system Shake Table.

Professor Haeri is a distinguished MSc graduate in Civil Engineering from Technical Faculty, University of Tehran, Iran (1976), MSc in Geotechnical Engineering from University of Illinois at Urbana-Champaign, USA (1979), and PhD in Earthquake Geotechnical Engineering from Imperial College of Science and Technology of University of London, UK (1988).

His research interest is fairly wide and mainly stays in the following subjects: soil characterization including unsaturated, cemented, collapsible and gravelly soils under static and dynamic loadings, earthquake geotechnical engineering (liquefaction, lateral spreading, landslide and local site effects including microzonation), static and dynamic behavior of earth and rockfill dams with particular focus on dynamic behavior of CFRD, physical modeling of geotechnical structures including piles under lateral spreading, soil structure interaction, deep excavations and related retaining structures, and implementation of soft computing in geotechnical engineering problems. Professor Haeri has published or contributed in writing 9 books in Farsi and has also published about 40 refereed international and national Journal papers, more than 12 nationally and internationally keynote or theme lectures, and more than 120 international and national conference papers. He has taught more than 10 different courses, graduated more than $10 \mathrm{PhD}$ students in Geotechnical
Engineering, and one in Engineering Geology and supervised more than 85 MS theses.

Professor Haeri is not only active in academic era, but also very active in Scientific and Technical Societies and Committees including Iranian Geotechnical Society. Moreover, he has been involved in different Committees for preparation of Code of Practice for Engineers including the Iranian Code for EarthquakeResistant Design of Buildings (Standard 2800) for a long time. In addition to his academic affairs, Professor Haeri is very active in advising and consulting the industry. He has been the Head and a Member of Panel of Experts in many important projects including the highest constructed under design arch dams in Iran (e.g., Karun IV Dam HPP, 230 m high, 1000 MW Power Plant, constructed and under operation, and Bakhtiari Dam, 315 m High, 2000 MW power plant, under design, etc.). He has been involved in designing, supervising, and advising very difficult and deep excavations in the City of Tehran and other cities and in many other professional and research projects.

Seyed Ali Shahcheraghi has graduated from Sharif University of Technology (SUT) in Civil Engineering with the first class honor. He was ranked third in the national Civil Engineering Olympiad and he has awarded membership to Iran's National Elites Foundation (INEF). He successfully finished his MSc studies on the dynamic behavior of calcite cemented gravely sand. He could publish several conference papers out of his MSc thesis. Afterwards, he has pursed his PhD study under supervision of Professor Haeri. His focus has been on the reliable evaluation of cyclic response of coarse-grained soils. He is currently writing up his $\mathrm{PhD}$ thesis to defend it and hopefully graduate from the university. Additionally, he has several years of experience in industry.

Hamed Sadeghi is the first graduate of the DualDegree PhD Program between the Hong Kong University of Science and Technology (HKUST) and Sharif University of Technology. He obtained both his degrees in Civil Engineering with excellent academic and research performance in 2016. His research has been mainly within two broad areas of unsaturated soil mechanics and geotechnical earthquake engineering. He has been the recipient of the Dr. Tavakoli Prize for conducting original research during his $\mathrm{PhD}$. In addition, he has been awarded several scholarships and grants from Iran's National Elites Foundation (INFE) for excellence in education and research. A 200-million IRR research grant, for example, was presented to him for fundamental investigation of critical state in collapsible soils. Dr. Sadeghi is currently a Visiting Assistant Professor at the Department of Civil Engineering at Sharif University of Technology. 